\title{
Nonsyndromic Type of Multiple Basal Cell Carcinoma
}

\section{${ }^{1}$ Chaturvedi Pankaj, ${ }^{2}$ Ghatge Amit, ${ }^{3}$ D'Cruz Anil, ${ }^{4}$ Pai Prathamesh, ${ }^{5}$ Chaukar Devendra ${ }^{6}$ Pantvaidya Gouri}

${ }^{1,4,5}$ Associate Professor, Department of Head and Neck Oncology, Tata Memorial Hospital, Parel, Mumbai Maharashtra, India ${ }^{2}$ Observer, Department of Head and Neck Oncology, Tata Memorial Hospital, Parel, Mumbai, Maharashtra India

${ }^{3}$ Professor and Head, Department of Head and Neck Oncology, Tata Memorial Hospital, Parel, Mumbai Maharashtra, India

${ }^{6}$ Assistant Professor, Department of Head and Neck Oncology, Tata Memorial Hospital, Parel, Mumbai Maharashtra, India

Correspondence: Ghatge Amit, Observer, Department of Head and Neck Oncology, Tata Memorial Hospital, Flat No. 2-16152, First Floor, 19, Vishwamohini Apartments, Besides Sunder Lodge, Samarth Nagar, Aurangabad-431001 (MS), Maharashtra India, Phone: +91-9322449343, +91-712-2745589 (Residence), Fax: +91-712-2745589, e-mail: doctoravg@gmail.com amitghatge@yahoo.com

\begin{abstract}
We report a case of nonsyndromic type of multiple basal cell carcinoma associated purely with actinic keratoses. A 69-year-old Indian male had suffered from multiple, variable-sized papules and nodules on the face, neck and chest for 13 years previous to treatment. He had no history of arsenic intake, irradiation, herb medication, or exposure to chemical warfare gases. Family histories for basal cell carcinoma and xeroderma pigmentosum were negative. Classical features of Gorlin's syndrome were conspicuous by their absence. Histopathologically, the tumors revealed typical findings of basal cell carcinoma arising from actinic keratoses. The case in point is a very rare and unique case in itself as being nonsyndromic, nonhereditary and occurring in the absence of various other environmental conditions as already mentioned in literature.
\end{abstract}

Keywords: Multiple basal cell carcinoma, actinic keratosis.

\section{INTRODUCTION}

Basal cell carcinoma is a slow-growing neoplasm of nonkeratinizing cells originating in the basal cell layer of the epidermis. It usually occurs as a single lesion in sun-exposed areas, although appearance of several lesions is not exceptional. It may be associated with arsenic exposure or predisposing conditions like actinic keratosis, Bowen's disease, leukoplakia, erythroplasia of Queyrat, keratoacanthoma, ${ }^{1}$ radiation dermatitis and xeroderma pigmentosum. ${ }^{2}$ It also occurs as a feature of variety of heredofamilial conditions like nevoid basal cell carcinoma syndrome (Gorlin's syndrome), ${ }^{3,4}$ Bazex's syndrome, Rombo syndrome, and unilateral basal cell nevus syndrome. Nevoid basal cell carcinoma syndrome or Gorlin's syndrome is inherited as an autosomal dominant trait and is characterized by range of developmental anomalies and predisposition to various cancers. Patients with this syndrome may exhibit a broad nasal root, borderline intelligence, jaw cysts, palmar pits, bilamellar clarification of falx cerebri and multiple skeletal abnormalities in addition to hundreds of basal cell carcinomas. ${ }^{4}$ In this patient we had ruled out the possibility of Gorlin's syndrome on history, clinical examination and investigations.

\section{CASE REPORT}

A 69 years old Indian man, a regional poultry farm officer was seen by us in February 2008. He had his office on an open lawn and where he used to work under direct sunlight. He presented with complaints of multiple, variable-sized, itchy papules and nodules that had gradually appeared in succession on the right nasolabial area, right submandibular region, left submandibular area, forehead midline, right supra-auricular region, right preauricular region, left temporal region, below the left nipple and still below it in the nipple line over approximately 13 years. These lesions could be differentiated as superficial, nodular, pigmented and morpheaform clinical variants of basal cell carcinoma (Figs 1 to 3). The lesions increased in size gradually over 


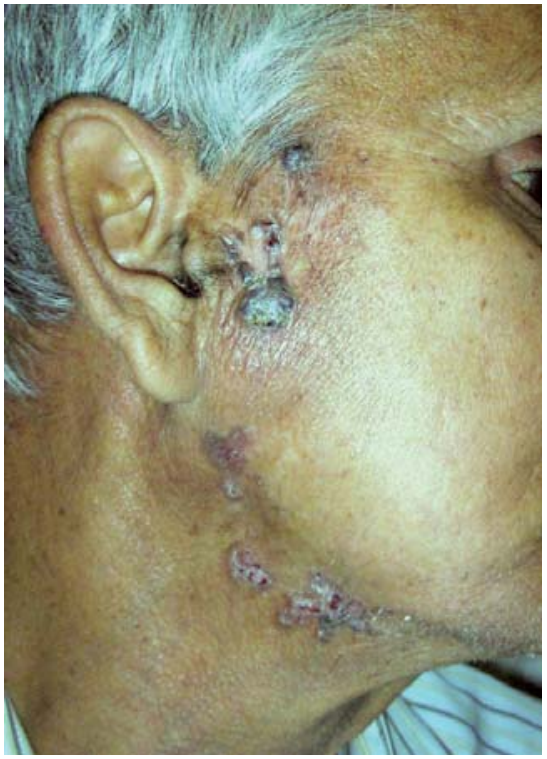

Fig. 1: Pigmented and nodular basal cell carcinomas in right preauricular region and morpheaform lesions in right submandibular region

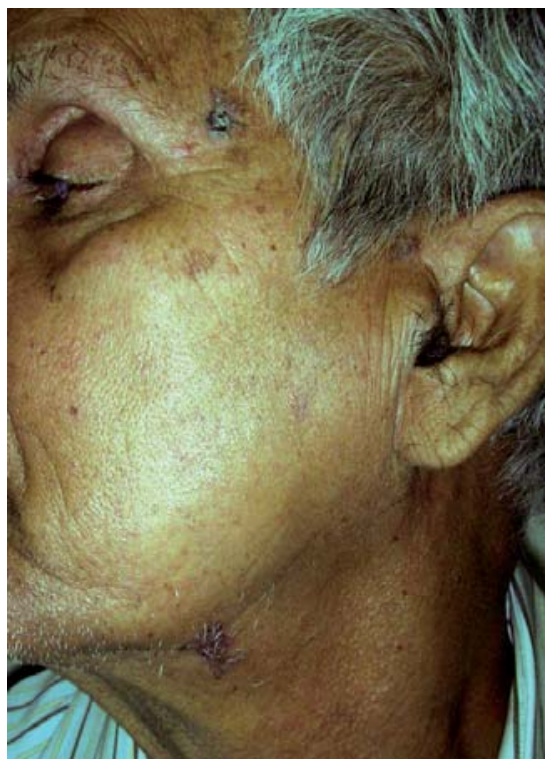

Fig. 2: Pigmented and superficial basal cell carcinomas in left temporal and submandibular regions respectively

time and desquamated in between. There were no regional lymphadenopathies. There was no history of associated medical or surgical illness. Familial and past histories were noncontributory.

CBC, urinalysis, coagulation profile, viral markers, serum biochemistry, liver function test, chest X-ray, ECG were within normal limits or negative. Diagnostic skin biopsy from the pigmented lesion on the right temporal region revealed basal cell carcinoma arising from actinic keratosis.

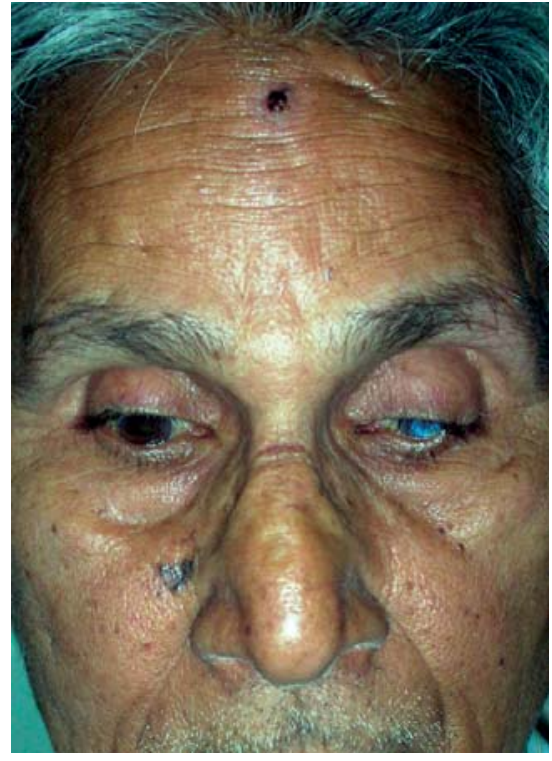

Fig. 3: Pigmented basal cell carcinomas in forehead midline and above the right nasolabial fold

All the nine tumors were completely removed by wide excision and primary closure of skin was done. The histopathology report of the tumors revealed multifocal basal cell carcinoma except for the chest wall nodule which turned out to be seborrheic keratosis. The patient is on regular follow-up.

\section{DISCUSSION}

Basal cell carcinoma is the most common human cancer. Basal cell carcinoma usually occurs as a single lesion, mainly on the face and neck. However, the occurrence of multiple lesions either simultaneously or subsequently is not uncommon. Basal cell carcinomas rarely metastasize, but they are locally invasive and can result in extensive morbidity through local recurrence and tissue destruction. Characteristically, basal cell carcinoma develops on sunexposed areas of lighter-skinned individuals, with 30\% of lesions occurring on the nose. However, it can occur anywhere, even in non sun-exposed areas.

The pathogenesis of basal cell carcinoma most commonly involves exposure to ultraviolet light (UVL), particularly rays in the UVB spectrum (290 to $320 \mathrm{~nm}$ ), which trigger mutations in tumor suppressor genes. Other factors that appear to be involved in the pathogenesis include mutations in regulatory genes; exposure to ionizing radiation, arsenicals, polyaromatic hydrocarbons, and psoralen-plusUVA therapy and alterations in immune surveillance. Basal cell carcinoma can be a feature of inherited conditions like 
the nevoid basal cell carcinoma syndrome (Gorlin's), Bazex's syndrome, Rombo syndrome, and unilateral basal cell nevus syndrome. Inactivation of the patched $(\mathrm{PTCH})$ gene $^{3}$ is probably a necessary step for basal cell carcinoma formation. UV-induced mutations in the p53 gene, such as CC and TT changes at dipyrimidine sites, have been reported in up to $60 \%$ of basal cell carcinomas as well. Basal cell carcinoma is associated with extremely low metastatic potential, but it does invade locally. It has a tendency to grow along the path of least resistance. Metastases, when reported, have involved the lung, lymph nodes, esophagus, oral cavity, and skin. Clinical variants of basal cell carcinoma include superficial, nodular, morpheaform (also termed aggressivegrowth basal cell carcinoma or infiltrative basal cell carcinoma), pigmented, fibroepithelioma of pinkus (FEP) and cystic basal cell carcinoma. Histologic subtypes of basal cell carcinoma include superficial, nodular and micronodular, and infiltrative basal cell carcinoma. The occurrence of multiple basal cell carcinomas in different clinical and environmental scenarios mentioned in literature has been depicted in the Table 1.

The case in point, however, is quite different from these cases reported in the literature. We had ruled out Gorlin's syndrome $^{3,4}$ on history, clinical examination and variety of investigations. Nonsyndromic but hereditary multiple basal cell carcinoma has also been reported in literature. ${ }^{5}$ Our case, however, had no positive family history either. Exposure to irradiation, ${ }^{6,7}$ arsenicals and sulphur mustard gas $^{8}$ was also ruled out. There was no evidence of xeroderma pigmentosum $^{2}$ or keratoacanthoma. ${ }^{1}$ Glutathione Stransferase (GSTM1 and GSTT1) and cytochrome P450 (CYP2D6) genotypes are found to be associated with multiple presentation phenotype of basal cell carcinoma and has already been mentioned in the literature. ${ }^{9}$ However, we did not insist on doing the PCR assay to rule out this genotype because of the financial constraints on the part of the patient. Moreover, doing so would not have changed the treatment plan or affected the therapeutic outcome. Thus, we categorized this patient as a rare case of nonsyndromic and nonhereditary type of multiple basal cell carcinoma and hence worth mentioning.

The treatment of basal cell carcinoma may be surgical or nonsurgical. ${ }^{10}$ Surgical techniques include excisional surgery (wide local excision with primary closure, flaps, grafts and secondary intention healing), curettage and cautery (scraping away the tumor and stopping bleeding with cautery), and cryosurgery (with liquid nitrogen) and Mohs' micrographic surgery. Nonsurgical techniques include radiotherapy, photodynamic therapy, topical flurouracil and topical imiquimod.

Cryosurgery does not provide any tissue for histopathological examination. Similarly, curettage samples do not provide adequate tissue to be able to examine tumor margins histologically. The main advantage of wide local excision is that excision margins can be examined histologically to check for tumor clearance.

Mohs' micrographic surgery ${ }^{10}$ is a special technique that offers high cure rates for basal cell carcinoma at high-risk sites (central face), morphiec tumors, and recurrent tumors, with maximal preservation of normal tissues. This comprises taking serial sections to be examined histologically until all margins are clear. It is the treatment method of choice for all recurrent and infiltrative basal cell carcinomas. Radiation therapy is best suited for older patients, particularly those with extensive lesions on the ear, lower limbs, or eyelids. Radiation therapy is not indicated for recurrent or morpheaform lesions and for young patients.

Topical photodynamic treatment is effective for superficial basal cell carcinoma. Another topical treatment for basal cell carcinoma is fluorouracil 5\% cream, which is useful in the management of multiple superficial basal cell carcinomas on the trunk and limbs. A newer topical immunomodulatory treatment is imiquimod $5 \%$ cream which holds good promise for treating superficial lesions.

\section{REFERENCES}

1. Sung Ku Ahn, et al. Multiple Basal Cell Carcinoma Associated with Keratoacanthoma. Yonsei Medical Journal 1992;33(3).

2. Malhotra Amit Kumar; Gupta Somesh, et al. Multiple basal cell carcinomas in xeroderma pigmentosum treated with imiquimod 5\% cream. Pediatric dermatology 2008;25(4):488-91.

3. LÜ Yan, ZHU Han-guang, et al. A new mutation of PTCH gene in a Chinese family with nevoid basal cell carcinoma syndrome. Chin Med J 2008;121(2):118-21.

4. Yousef Alghamdi. Skin tags as a presenting sign of basal cell nevus syndrome in three sisters of the same family: A Case Report. Ann Saudi Med 2008;28(2):132-34.

5. Rudolf Happle. Nonsyndromic type of hereditary multiple basal cell carcinoma. American Journal of Medical Genetics 95:2161-63.

6. Review By. Kevin Berman, MD, PhD, Associate, Atlanta Center for Dermatologic Disease, Atlanta, GA.

7. Karadudak O, Dogan B. Multiple basal cell carcinomas following irradiations for Hodgkin's disease. Balkan Military Medical Review 2007;10:178-80. 
Table 1: Occurrence of multiple basal cell carcinoma in different scenarios

\begin{tabular}{ll}
\hline $\begin{array}{l}\text { SI. } \\
\text { no. }\end{array}$ & Author, study, journal and year \\
\hline 1. & $\begin{array}{l}\text { LÜ Yan, ZHU Han-guang et al. } \\
\text { mutation of PTCH gene in a Chinese }\end{array}$ \\
& family with nevoid basal cell carcinoma \\
& syndrome. Chin Med J 2008;121(2):118-21.
\end{tabular}

2. Yousef Alghamdi. ${ }^{4}$ Skin tags as a presenting sign of basal cell nevus syndrome in three sisters of the same family: A Case Report. Ann Saudi Med 2008;28(2):132-34.

3. Sudarshan Ramachandran, John T.

Lear et al. ${ }^{9}$ Presentation with multiple cutaneous basal cell carcinomas: Association of glutathione S-transferase and cytochrome P450 genotypes with clinical phenotype. Cancer epidemiology, biomarkers and prevention January 1999;8:61-67.

4. Review By: Kevin Berman, ${ }^{6}$ Associate, Atlanta center for dermatologic disease, Atlanta, GA.

5. $\quad$ Sung Ku Ahn et al. ${ }^{1}$ Multiple Basal Cell Carcinoma Associated with Keratoacanthoma. Yonsei Medical Journal 1992;33(3).

6. Karadudak $\mathrm{O}$, Dogan $\mathrm{B}^{7}$ multiple basal cell carcinomas following irradiations for Hodgkin's disease. Balkan military medical review 2007;10:178-80.

7. Rashidi T, MD. ${ }^{8}$ Occurrence of multiple basal cell carcinomas in a chemical warfare victim. Medical journal tabriz university of Medical Sciences Autumn 2008;30(3).

8. Rudolf Happle. ${ }^{5}$ Non-syndromic type of hereditary multiple basal cell carcinoma. American Journal of Medical Genetics 95(2):161-63.

9. Malhotra Amit Kumar, Gupta Somesh, et al. ${ }^{2}$ Multiple basal cell carcinomas in xeroderma pigmentosum treated with imiquimod $5 \%$ cream. Pediatric dermatology 2008;25(4):488-91.

$\begin{aligned} & \text { Presentation and } \\ & \text { diagnosis }\end{aligned}$
Nevoid basal cell
carcinoma syndrome
(Gorlin's syndrome)
Skin tags presenting as
Nevoid basal cell carcinoma
Syndrome (Gorlin's
syndrome)

Multiple basal cell carcinoma

Multiple basal cell carcinoma

Multiple basal cell carcinoma

Keratoacanthoma

Multiple basal cell carcinoma (24 lesions on back)

Multiple basal cell carcinoma

Multiple basal cell carcinoma

Multiple basal cell carcinoma
X-ray therapy for acne

Chemical warfare gas (Sulphur mustard)

Nonsyndromic type of multiple basal cell

carcinoma

Causes or associated conditions

Mutation of PTCH gene

Mutation of PTCH gene

Glutathione S-Transferase and Cytochrome P450 Genotypes

Irradiation for Hodgkin's disease

Xeroderma pigmentosum
Treatment

Not within the purview of study

Snipping off those pedunculated lesions followed by cryotherapy to the base, photoprotection and genetic counseling

Not within the purview of study

Not within the purview of study

Excisional biopsies and electrocauterization.

Cryotherapy, excisional biopsy, imiquimod topically five times per week for six weeks and intralesional interferon alpha-2a

Wide local excision

Not within the purview of study

Imiquimod 5\% cream.
8. Rashidi T, MD. Occurrence of Multiple Basal Cell Carcinomas in a Chemical Warfare Victim. Medical Journal Tabriz University of Medical Sciences Autumn 2008;30:3.

9. Sudarshan Ramachandran, John T Lear, et al. Presentation with Multiple Cutaneous Basal Cell Carcinomas: Association of
Glutathione S-Transferase and Cytochrome P450 Genotypes with Clinical Phenotype. Cancer Epidemiology, Biomarkers and Prevention January 1999;8:61-67.

10. CSM Wong, RC Strange, JT Lear. Basal cell carcinoma. British Medical Journal 2003;327;794-98. 